\title{
Die relatiewe belangrikheid van verskillende evalueringskriteria by die koop van 'n passasiersvoertuig: 'n Vergelykende studie van mans en vroue
}

\author{
P.J. du Plessis* \\ Skool vir Bedryfsleiding, Universiteit van Suid-Afrika, Posbus 392, Pretoria, 0001 Republiek van Suid-Afrika \\ C. Boshoff \\ Departement Bedryfsekonomie, Universiteit Vista, Privaatsak X613, Port Elizabeth, 6000 Republiek van Suid-Afrika
}

Ontvang 27 Augustus 1987; aanvaar 21 September 1987

\begin{abstract}
A number of studies revealed that the role of women both as influencer and independent decision-maker is becoming increasingly important in the buying decision involving the purchase of a passenger vehicle. In today's highly competitive South-African motor vehicle market it is becoming vital that motor manufacturers pay greater attention to market needs - specially with regard to important market segments. This study analyses certain aspects of the market segment consisting of women. The null-hypothesis this study tested was that there are no differences between male and female consumers pertaining to the relative importance of evaluation criteria, when purchasing a passenger vehicle. By means of analysis of variance it was established that there are significant differences $(P<0,01)$ between men and women with regard to 15 of the 65 evaluation criteria. It was also found that there are 50 insignificant differences between the two groups. The hypothesis, as formulated is thus rejected, with regard to 15 of the evaluation criteria, in favour of the alternate hypothesis.
\end{abstract}

Verskeic studies het aan die lig gebring dat die rol van die vrou, hetsy as beïnvloeder of as onafhanklike besluitnemer, by die aankoop van 'n motorvoertuig al hoe belangriker word. Teen die agtergrond van ' $n$ mededingende Suid-Afrikaanse motormark is dit noodsaaklik dat motorvervaardigers hul aandag toenemend moet toespits op dic bevrediging van markbehoeftes - veral ten opsigte van belangrike individuele marksegmente. Hierdic studie plaas die marksegment wat uit vroue bestaan, onder die soeklig. Die nulhipotese wat in die studie getoets is, is dat daar geen verskille tussen manlike en vroulike verbruikers bestaan, betreffende die relatiewe belangrikheid van evalueringskriteria by die aankoop van 'n passasiersvoertuig nie. Met behulp van variansie-ontleding is daar vasgestel dat beduidende verskille $(P<0,01)$ ten opsigte van 15 uit die 65 evalueringskriteria met betrekking tot mans en vroue bestaan. Onbeduidende verskille kom by 50 evalueringskriteria voor. Die alternatiewe hipotese word daarom met betrekking tot 15 evalueringskriteria aanvaar.

* Aan wie korrespondensie gerig moet word

\section{Inleiding}

Die Suid-Afrikaanse motorbedryf word gekenmerk deur 'n relatief groot aantal vervaardigers wat 'n betreklik klein mark bedien. Die gevolg is 'n hoogs mededingende mark waarin die winsgrense van beide vervaardigers en handelaars onder druk verkeer. In die lig hiervan word verwag dat die Suid-Afrikaanse motormark, teen ongeveer 1990, deur slegs vyf in plaas van die huidige sewe vervaardigers bedien sal word (McCarthy, 1987 : 34). Dit is dus duidelik dat vervaardigers wat wil oorleef hul aandag toenemend op die bevrediging van verbruikersbehoeftes sal moet toespits.

Teen die agtergrond van toenemende mededinging in die Suid-Afrikaanse motormark is dit noodsaaklik dat motorvervaardigers bewus is van markbehoeftes ook ten opsigte van individuele marksegmente. In hierdie studie word die segment van die mark wat uit vroue bestaan, onder die soeklig geplaas.

Verskeie studies het bevind dat die rol van die vrou, hetsy as beinvloeder of as onafhanklike besluitnemer by die aankoop van 'n motor, al hoe belangriker word (Davis 1970; Cunningham \& Green 1970; Venkatesh 1980; Baran 1981; Condé Nast 1984; en Madejchick 1985). Indien verder in ag geneem word dat $45 \%$ van die uitgereikte ligtemotorvoertuig-lisensies deur vroue besit word, is dit duidelik dat die potensiaal van dié segment van die mark nie geïgnoreer kan word nie. Dit is egter 'n marksegment wat ten opsigte van navorsing nie tot sy reg kom nie. Condé Nast (in Ad Forum 1985) het gepoog om 'n belangrikheidshierargie te bepaal van faktore wat vroue by motoraankope oorweeg, terwyl King \& King (1980) bevind het dat daar geen beduidende verskille tussen die persepsies van mans en vroue ten opsigte van 'n motor as statussimbool bestaan nie. Geen wetenskaplik verantwoorde studie is egter nog in Suid Afrika gedoen om te bepaal of en in watter mate mans en vroue verskil ten opsigte van die evaluasie van verskillende aankoopkriteria nie. Hierdie studie is 'n poging om dié leemte te vul.

\section{Probleemstelling}

Die vraag wat hierdie studie poog om te beantwoord is of daar verskille bestaan tussen die manlike en vroulike verbruiker met betrekking tot die relatiewe belangrikheid wat elke groep aan evalueringskriteria heg, by die aankoop van 'n passasiersmotor.

Die hipotese wat in verband met die voorgaande probleem geformuleer is, is dat daar geen verskille 
tussen manlike en vroulike verbruikers bestaan betreffende die relatiewe belangrikheid van evalueringskriteria by die aankoop van 'n passasiersmotor nie.

\section{Metodologie}

Vorige navorsing oor verbruikersgedrag by die aankoop van 'n motorvoertuig kan moontlik gekritiseer word op grond daarvan dat inligtingsinwinning plaasgevind het na 'n redelike lang tydsverloop nadat die voertuig gekoop is. Behalwe dat inligting nie meer so vars in die verbruiker se geheue is nie, kon veranderlikes soos dissonansie-invloede (byvoorbeeld ervaring met die motor en diens van die handelaar) die respondent se ware, oorspronklike koopmotiewe sodanig beïnvloed het, dat die werklike redes en wyse waarop besluitneming toe plaasgevind het, in 'n groot mate versluier word. Om hierdie moontlike leemte uit te skakel, het respondente in hierdie studie (die kopers van passasiersvoertuie), 'n gestruktureerde vraelys op die motorhandelaar se perseel voltooi onmiddellik nadat 'n voertuig gekoop is. Sodanige werkswyse het die voordeel dat inligtingsinwinning plaasvind terwyl al die faktore wat in die besluitnemingsproses ' $n$ rol gespeel het, nog vars in die geheue van die respondent is.

Dic benadering tot inligtingsinwinning wat gebruik is, het die trekking van twee steekproewe genoodsaak, naamlik 'n handelaarssteekproef en 'n verbruikerssteekproef. Die handelaarssteekproef het bestaan uit motorhandelaars by wie respondente vraelyste kon voltooi terwyl die verbruikerssteekproef uit die respondente self bestaan het.

Vanweë die hoë mate van geografiese konsentrasie van voertuigeienaars in Suid-Afrika, asonk weens koste en tydsoorwegings is die universum vir beide steekproewe tot metropolitaanse gebiede beperk. Vir die doeleindes van die studie word die verbruikerssteekproef gedefinieer as alle Blankes, Kleurlinge, Asiërs en Swartes wat 'n passasiersmotorvoertuig gedurende die tydperk Desember 1985 tot Mei 198 gekoop het by handelaars in die PWV-, Durban-, e Kaapstadgebied.

Die keuse van 'n verbruikerssteekproef was onderhs wig aan die deelname van handelaars aangesie laasgenoemde die funksie van 'veldwerker' vervul he' Kriteria aan die hand waarvan handelaars vir deelnam aan die studie opgeneem is, was die volgende:

- verteenwoordiging van elk van die sew motorvervaardigers (in 1985) vir elke streek, i verhouding tot hul markaandeel in die Suic Afrikaanse passasiersmotormark;

- verteenwoordigende aantal gebruikt motorhandelaars wat nie aan motorvervaardiges agentskappe gekoppel is nie;

- ordegrootte van die handelaar se motorverkope; eı - bereidwilligheid om deel te neem.

Aangesien geen gemeenskaplike register van all motorhandelaars in Suid-Afrika bestaan nie, is va bronne soos die ledelyste van die National Automobil Dealers Association, die Auto Dealers Guide en di Departement van Pos- en Telekommunikasie $s$ Geelbladsye Gids gebruik gemaak om handelaars in di genoemde gebiede by die universum in te sluit. In totac is 871 handelaars (nuwe en gebruikte motors geïdentifiseer waarvan 125 bereid was om aan die studi deel te neem. In Tabel 1 word die besonderhede van di streke, tipe handelaar en aantal vraelyste wat aa motorhandelaars vir voltooiing deur motorkoper oorhandig is, aangetoon.

Wat die verbruikerssteekproef betref, is van' kombinasie van oordeel en kwotasteekproeftrekkin gebruik gemaak in die studie, terwyl die final steekproef gestratifiseer is ten opsigte van geografies gebied sodat voldoende voorsiening gemaak kon wor vir die natuurlike konsentrasie van sekere rassegroepe $i$ sommige gebiede.

Tabel 1 Steekproef van handelaars in geselekteerde streke

\begin{tabular}{|c|c|c|c|c|c|c|c|c|}
\hline \multirow{4}{*}{$\begin{array}{l}\text { Tipe } \\
\text { handelaar/ } \\
\text { agentskap }\end{array}$} & \multicolumn{6}{|c|}{ Streek } & & \\
\hline & \multicolumn{2}{|c|}{ PWV } & \multicolumn{2}{|c|}{ Durban } & \multicolumn{2}{|c|}{ Kaap } & \multicolumn{2}{|c|}{ Totaal } \\
\hline & \multicolumn{2}{|c|}{ Aantal } & \multicolumn{2}{|c|}{ Aantal } & \multicolumn{2}{|c|}{ Aantal } & \multicolumn{2}{|c|}{ Aantal } \\
\hline & handelaars & vraelyste & handelaars & vraelyste & handelaars & vraelyste & handelaars & vraelyste \\
\hline BMW & 4 & 135 & 1 & 15 & 1 & 20 & 6 & 170 \\
\hline Samcor-Ford & 6 & 420 & 2 & 35 & 2 & 30 & 10 & 485 \\
\hline$-\mathrm{MMI}$ & 7 & 315 & 3 & 140 & 3 & 112 & 13 & 567 \\
\hline General Motors & 4 & 235 & 2 & 100 & 3 & 110 & 9 & 445 \\
\hline \multicolumn{9}{|l|}{ Mercedes-Benz/ } \\
\hline Honda & 6 & 295 & 1 & 30 & 1 & 35 & 8 & 360 \\
\hline Nissan & 6 & 240 & 2 & 150 & 2 & 70 & 10 & 460 \\
\hline Toyota & 10 & 520 & 2 & 90 & 3 & 220 & 15 & 830 \\
\hline Volkswagen & 7 & 330 & 2 & 60 & 2 & 70 & 11 & 460 \\
\hline Gebruikte motors & 8 & 215 & 3 & 70 & 5 & 85 & 16 & 370 \\
\hline Renault & 4 & 101 & 1 & 10 & 1 & 10 & 6 & 121 \\
\hline Totaal & 62 & 2806 & 19 & 700 & 23 & 762 & 104 & 4268 \\
\hline
\end{tabular}


Tabel 3 Geslagsverspreiding van verbruikersteekproef

\begin{tabular}{|c|c|c|c|c|c|c|c|c|c|c|}
\hline \multirow[b]{3}{*}{ Geslag } & \multicolumn{8}{|c|}{ Rassegroep } & & \\
\hline & \multicolumn{2}{|c|}{ Blankes } & \multicolumn{2}{|c|}{ Kleurlinge } & \multicolumn{2}{|c|}{ Asiërs } & \multicolumn{2}{|c|}{ Swartes } & \multicolumn{2}{|c|}{ Totaal } \\
\hline & Aantal & $\begin{array}{l}\% \text { van } \\
\text { blankes }\end{array}$ & Aantal & $\begin{array}{c}\% \text { van } \\
\text { kleurlinge }\end{array}$ & Aantal & $\begin{array}{l}\% \text { van } \\
\text { Asiërs }\end{array}$ & Aantal & $\begin{array}{l}\% \text { van } \\
\text { Swartes }\end{array}$ & Aantal & $\%$ \\
\hline Manlik & 451 & 78,2 & 95 & 83,3 & 97 & 95,1 & 93 & 85,3 & 737 & 81,7 \\
\hline \multirow[t]{2}{*}{ Vroulik } & 126 & 21.8 & 19 & 16,7 & 5 & 4,9 & 16 & 14.7 & 165 & 18,3 \\
\hline & \multicolumn{2}{|c|}{$n=577$} & \multicolumn{2}{|c|}{$n=114$} & \multicolumn{2}{|c|}{$n=102$} & \multicolumn{2}{|c|}{$n=109$} & \multicolumn{2}{|c|}{$n=902$} \\
\hline
\end{tabular}

Tabel 2 Geografiese verspreiding van verbruikersteekproef

\begin{tabular}{lcc}
\hline Gebied & Aantal respondente & $\%$ van totaal \\
\hline PWV-gebied & 547 & 60,7 \\
Durban-Pinctown & 170 & 18,8 \\
Kaapstad & 185 & 20,5 \\
Totaal & 902 & 100,0 \\
\hline
\end{tabular}

'n Totaal van 968 vraelyste is van verbruikers terug ontvang waarvan 902 bruikbaar was.

Die verspreiding van respondente volgens geografiese gebied word in Tabel 2 aangetoon.

Tabel 2 toon dat die verspreidingsverhouding tussen die PWV-, Durban-, en Kaapstadgebied onderskeidelik 3:1:1 is. Die verspreiding van werklike motorregistrasies tussen die drie gebiede is $4: 1: 1$ en die proporsionele verhouding tussen die drie gebiede word as aanvaarbaar beskou.

Die geslagsverspreiding van die verbruikerssteekproef word in Tabel 3 aangetoon.

Tabel 3 toon dat die verbruikerssteekproef uit 737 mans en 165 vroue bestaan het. Vroue het dus $18,3 \%$ van die verbruikerssteekproef uitgemaak waarvan $76,4 \%$ blanke vroue was. Ofskoon vroue ongeveer $45 \%$ van uitgereikte ligte motorvoertuiglisensies besit, is werklike motorregistrasies volgens geslag, of statistiek oor die omvang van motoreienaarskap deur vroue, nie amptelik beskikbaar nie, alhoewel dit na raming ongeveer $20 \%$ is (Wierenga, 1985: 52).

In die verbruikersvraelys is 65 kriteria wat 'n verbruiker by die aankoop van 'n passasiersmotor in ag kan neem aan respondente voorgehou (Du Plessis, 1986: 188-191). Responsies op elke kriterium word op 'n sespuntskaal van een tot ses aangeslaan. Die skaalwaarde van een dui aan dat die kriterium vir die respondent totaal onbelangrik was by die keuse van die betrokke motor, terwyl 'n waarde van ses besondere belangrikheid aantoon. Die skaalwaardes kan gedefinieer word as diskrete posisies op 'n veronderstelde kontinuum van belangrikheid vir die respondent (Boote, 1981: 54).
Tabel 4 Gemiddeldes, standaardafwykings en $F$ waardes van evalueringskriteria wat beduidend verskillend ${ }^{a}$ deur mans en vroue geëvalueer is

\begin{tabular}{|c|c|c|c|c|c|}
\hline \multirow{2}{*}{$\begin{array}{l}\text { Beskrywing van } \\
\text { kriterium }\end{array}$} & \multicolumn{2}{|c|}{$\begin{array}{c}\text { Mans } \\
n=737\end{array}$} & \multicolumn{2}{|c|}{$\begin{array}{c}\text { Vroue } \\
n=165\end{array}$} & \multirow[b]{2}{*}{$F$-waarde } \\
\hline & $\bar{x}$ & $s$ & $\bar{x}$ & $s$ & \\
\hline \multicolumn{6}{|l|}{ Verhouding met verkoop- } \\
\hline personeel van handelaar & 3,921 & 1,482 & 4,194 & 1.427 & 7,75 \\
\hline Luuksheid binne & 4,261 & 1.023 & 4,048 & 1,141 & 9,36 \\
\hline Brandstofdoeltreffendheid & 5,115 & 0,982 & 5,297 & 0.835 & 8,16 \\
\hline Enjinkrag & 4.728 & 0.995 & 4.527 & 1.124 & 8,76 \\
\hline Gerief vir passasiers & 4,110 & 1.082 & 3,806 & 1,292 & 16,52 \\
\hline Hoëspoedverrigting & 3.958 & 1.236 & 3,648 & 1.268 & 14.05 \\
\hline Rygemak & 4,874 & 0,950 & 4,703 & 1,001 & 7,16 \\
\hline Reikafstand van brandstoftenk & 4,780 & 1.045 & 4,606 & 1,157 & 6.00 \\
\hline Padhouvermoë & 5,137 & 0.934 & 4.939 & 1.004 & 9.85 \\
\hline Ruimheid vir bestuurder & 4,650 & 1,022 & 4,412 & 1,076 & 11,99 \\
\hline Ruimheid vir agterpassasiers & 3,938 & 1,129 & 3,733 & 1,307 & 7,00 \\
\hline Beenruimte voor & 4,707 & 0.978 & 4,533 & 1.045 & 6,96 \\
\hline Mening van familie & 3,503 & 1,340 & 3,218 & 1,449 & 9,90 \\
\hline Tegniese gevorderdheid & 4,533 & 1.043 & 4,255 & 1,238 & 14,91 \\
\hline Voorwielaandrywing & 3.086 & 1,429 & 3,358 & 1,518 & 7,98 \\
\hline
\end{tabular}

aeduidend op die 0,01-vlak

\section{Resultate en Bespreking}

Die geformuleerde hipotese is met behulp van eenrigting variansie-ontleding getoets ( $F$-toets). Die gemiddeldes en standaardafwykings van die kriteria wat beduidend verskillend (op die 0,01-vlak) deur mans en vroue geëvalueer is, word in Tabel 4 aangetoon.

Tabel 4 toon dat die grootste verskille tussen mans en vroue met betrekking tot hulle evaluering van die relatiewe belangrikheid van die kriteria by gerief vir passasiers $(F$-waarde $=16,52)$, tegniese gevorderheid $(F$-waarde $=14,91)$, hoëspoedverrigting $(F$-waarde $=$ $14,05)$, ruimheid vir bestuurder $(F$-waarde $=11,99)$ en mening van familie ( $F$-waarde $=9,90)$, voorkom. Alhoewel nie ' $n$ doelwit van die studie nie, kan bespiegel word dat verskille wat byvoorbeeld voorkom by kriteria soos gerief vir passasiers, toegeskryf kan word aan die moontlikheid dat mans motors vir gesinsdoeleindes 
Tabd 5 Belangridheidsvolgorde van evalueringskiteria vir marke en voulike respondente

\begin{tabular}{|c|c|c|c|}
\hline \multirow[b]{2}{*}{ Bedingexe in kmerum } & \multicolumn{3}{|c|}{ Rangerde } \\
\hline & Total & Manlik & Vroulik \\
\hline Brandwotductireffend thend & 1 & 1 & 1 \\
\hline Betroubuertiend ian dic modet & 2 & 2 & 2 \\
\hline Padhouvermax & 3 & 3 & 7 \\
\hline Gehatie ian vakmanskap & 4 & 4 & 5 \\
\hline Instancthoudingakaste & 5 & 5 & 3 \\
\hline Lat boptisut & 6 & 6 & 4 \\
\hline Beskikbaarhed san onderdele & 7 & 7 & 8 \\
\hline Werkverngane van enjin & 8 & 8 & 11 \\
\hline Veilizheidskenmerte & 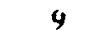 & $\varphi$ & 9 \\
\hline Aankrepprys & l1) & 10 & 10) \\
\hline Kosie van onderdek & 11 & 11 & 6 \\
\hline Reputane ban motorvenaardiget & 12 & 12 & 12 \\
\hline Gemak van bestuut & 13 & 13 & 13 \\
\hline Enjintrag & 14 & 14 & $\bullet$ \\
\hline Rygemak & 15 & 15 & 15 \\
\hline Onbeperkte urtsg & • & $\cdot$ & 14 \\
\hline
\end{tabular}

- Vie onder dx 15 belangrikste ev alueringskriteria gerang nie

gekoop het terwyl vroue voentuie vir besigheidsdoeleindes of die vervoer van kinders gekoop het.

Aangesien onbeduidende verskille by 50 evalueringskriteria $(77 \%)$ voorkom, word die nul-hipotese met betrekking tot 15 evalueringskriteria verwerp. ten gunste van die alternatiewe hipotese.

Respondente is ook gevra om die sewe belangrikste evalueringskriteria op in ranglys te plaas. Die gesommeerde frekwensies van die sewe belangrikste kriteria soos deur die respondente geselekteer. is as basis gebruik om die belangrikheidsvolgorde van die kriteria te bepaal. Die resultate, vir mans en vroue afsonderllk. asook die totaal, word in Tabel 5 aangetoon.

Tabel 5 toon dat beide mans en vroue brandstofdoeltreffendheid en betroubaarheid van die model onderskeidelik as die belangrikste en naasbelangrikste kriteria beskou. Vir vroue is padhouvermoë, gehaite van vakmanskap, werkverrrigting van enjin. rygemak en enjinkrag relatief onbelangriker as wat dit die geval vir mans is. Instandhoudingskoste, lae loopkoste en koste van onderdele is relatief belangriker vir vroue as vir mans. Condé Nast (1981) se bevinding dat vroue meer klem op brandstofekonomie, versnelling en herverkoopwaarde sal lê, is slegs geldig ten opsigte van hierdie studie se bevinding oor brandstofdoeltreffendheid. Daar behoort egter in gedagte gehou te word dat die versameling van veranderlikes wat in die twee studies gebruik is, nie identies is nie.

\section{Slotopmerkings en Aanbevelings}

Die belangrikheid van vroue as onafhanklike besluitnemers en belangrike deelgenote by die aankoop van 'n motorvoertuig, asook die potensiaal wat dié marksegment bied, noodsaak motorvervaardigers om toenemend aandag aan dié marksegment te skenk.

Bevindinge dat vroue byoorbeeld instandhoudingskoste. lae loopkoste en koste san onderdele as relatief belangriker as mans beskou. suggereer dat hierdie kriteria meer deur bemarkers beklemtoon behoon te word. Kriteria soos hoëspoed errigting. padhousermoè. mening van familie. ruimheid sir bestuurder. gerief vir passasiers en tegniese gevorderdheid is sir mans belangriker as vir vroue. Hierdie aspekte hou belangrike implikasies vir die bemarker van passasiersıoertuie in. veral ten opsigte van marksegmentering. die keuse van teikenmarkte en die beplanning en uitvoering van in kommunikasiestrategie.

\section{Summary}

The South African motor industry is characterized by a relatively large number of manufacturers serving a fairly small market. The result is a highly competitive market with the profit margins of both manufacturers and dealers under constant pressure. It is thus expected that the South African market will. by 1990 . be served by five instead of the current seven manufacturers. Manufacturers who wish to survive and grow will therefore have to pay greater attention to market needs. specially regarding important market segments.

A number of studies revealed that the role of women, both as influencers and independent decision-makers is becoming increasingly important in the buying decision involving the purchase of a passenger vehicle. In the light of this trend. this study analysed certain aspects of the market segment consisting of women.

The study was conducted to determine the relative importance of various evaluation criteria for both males and females when buying a motor vehicle. The sample consisted of 902 consumers of all race groups in metropolitan areas in South Africa. who bought a new or used car for private use during the period December 1985 to May 1986. The sample consisted of 737 males and 165 females.

Sixty-five evaluation criteria were used in a selfadministered structured questionnaire. Consumers had to complete the questionnaire in the dealer's showroom after the deal was closed. Their perception of the relative importance of each criterion was determined on a sixpoint scale which ranged from 1 (totally unimportant) to 6 (extremely important).

The null-hypothesis tested in this study was that there are no differences between male and female consumers pertaining to the relative importance of evaluation criteria, when purchasing a passenger vehicle.

By means of analysis of variance it was found that there are significant differences $(P<0.01)$ between the groups with regard to 15 of the 65 evaluation criteria, that could be rated. The null-hypothesis, as formulated is thus rejected with regard to 15 of the evaluation criteria in favour of the alternate hypothesis.

\section{Verwysings}

Baran, R.J. 1981. Patterns of decision-making influence for selected products and services in the changing marketing 
environment : new theories and applications. Ed.

Bernhard, K., et al., 1981. Educators' Conf. Proc.. Chicago: American Marketing Association.

Boote, A.S. 1981. Reliability testing of psychographic scales. J. Advert. Res. vol. 21, (October).

Condé Nast Publications Inc. 1984. The women's market for cars. (November). Research Commissioned by G.D. Power and Associates, Los Angeles, California.

Cunningham, I.C.M. \& Green, R.T. 1970. Marketing notes and communications. Purchasing roles in the U.S. family, 1955 and 1973. J. Market. vol. 38 (October).

Davis, H.I. 1970. Dimensions of marital roles in consumer decision making. J. Market. Res. vol. 7 (May).

Du Plessis, P.J. 1986. Verbruikersgedrag by die aankoop van 'n motorvoertuig. Ongepubliseerde DBL-proefskrif.

Pretoria: Universiteit van Suid-Afrika.
King, A.B. \& King, J.P. 1980. The impact of changing market conditions on consumer perceptions of the automobile as a status symbol. In: Developments in marketing science, vol. III. Ed. Venkatakrishna, V.B. 1980. Proceedings of the fourth annual conference of the Acadamy of Marketing Science, Dallas, Texas (April 30 - May 3).

Madejchick, J. 1985. Car makers accelerate efforts to market to women. Ad Forum.

McCarthy, B. 1986. Shades of light and dark: The South African motor industry - Yesterday, today and tomorrow. Investment in 1987. Supplement to Financial Mail, November 28.

Venkatesh, A. 1980. Changing roles of women - a life style analysis. J. Consumer Res. vol. 7 (September).

Wierenga, J. 1985. Vervaardigers vry kliphard na vroue. Huisgenoot, 17 Oktober. 